\title{
HET SURINAMEVRAAGSTUK
}

\author{
DOOR
}

MR. O. E. G. GRAAF VAN LIṂBURG STIRUM

Dat dit vraagstuk zeer veelzijdig is, werd reeds zoo herhaaldelijk betoogd, dat het nauwelijks geoorloofd mag worden geacht, daarop nogmaals de aandacht te vestigen, ware het niet, dat juist in den laatsten tijd de belangstelling voor Suriname zoo verblijdend toeneemt, dat het inderdaad nuttig kan zijn, nogeens bij dit veelzijdig onderwerp stil te staan.

Voornamelijk sedert het rapport der Suriname Commissie, dat in 1911 verscheen, is dit vraagstuk van allerlei kanten in tallooze schrifturen bezien en zijn vele middelen aan de hand gedaan, om verandering en verbetering te brengen in toestanden, over welker onhoudbaarheid ieder het eens was, doch omtrent welker verbetering de meeningen zeer uiteen liepen. Doch niettegenstaande dit alles deed men in het moederland niets of vrijwel niets, om eenige verbetering aan te brengen en wat men deed was lapwerk. Het strekt dan ook den huidigen Minister van Koloniën tot groote eer, dat hij reeds zoo kort na zijn ambtsaanvaarding zich niet heeft verscholen achter het voorwendsel, dat hij zich eerst een eigen meening omtrent de Surinaamsche quaestie moest vormen, maar dat daarvoor voorloopig in verband met de grootere belangen van Oost-Indië vermoedelijk geen gelegenheid zoude bestaan, doch terstond heeft begrepen, dat nu eindelijk aan deze zijde van den Oceaan eens iets positiefs moest geschieden, terwijl ook gelukkig de Tweede Kamer der Staten Generaal door de begrooting, waarin de Minister de voorstellen van den Ondernemersraad voor Suriname in hoofdzaak had verwerkt, aan te nemen, getoond heeft, 
voor de belangen niet alleen van Suriname maar ook indirect voor die des Rijks een open oog te hebben. En dan gebiedt de billijkheid, dat in dit verband een woord van groote hulde wordt gebracht aan den man, die met onverwoestbaar optimisme en nimmer verflauwende energie heeft gearbeid, ja heeft gesloofd en geslaafd voor de belangen van het hem toevertrouwde gebiedsdeel en voor wien het thans bereikte resultaat ongetwijfeld een groote voldoening zal zijn, al zal hij de eerste wezen, om te erkennen, dat dit slechts een eerste - zij het dan ook zeer belangrijke - stap is op den weg van herstel. Het woord is thans aan het Nederlandsche kapitaal, dat moge toonen, dat ook dat gedeelte van ons Nederlandsche volk zich van zijn plicht bewust is en bovendien zijn eigen welbegrepen belang, hetwelk tevens dat van het geheele volk is, voor oogen heeft.

Ongemerkt is echter vooruitgeloopen op de bedoeling van deze bijdrage, om het een en ander te zeggen omtrent een der vele bovengenoemde schrifturen, n.l. het zeer uitgebreide artikel van den Heer H. G. Brandon in den 6en jaargang van dit tijdschrift (1924/25) onder den titel „Het Surinamevraagstuk”. De schrijver poneert de stelling, dat het bij dit vraagstuk gaat „om het vinden van wijzen en middelen, om een kleine bevolking in een "groot vruchtbaar tropengebied in staat te stellen, zich „een goed bestaan te verwerven in haar land en een krach„tig gezond welvarend en bloeiend gemeenebest te vor"men."

Het wil mij voorkomen, dat deze stelling te beperkt is. Het gaat er toch niet alleen om, de thans aldaar wonende inderdaad kleine bevolking in gunstiger conditie te brengen, doch om het geheele gebiedsdeel uit zijn verval op te heffen. Dat dit met de thans aanwezige bevolking zou zijn te bereiken, lijkt mij toch wel wat al te optimistisch geredeneerd en in strijd met de ervaring, sinds de afschaffing der slavernij opgedaan. Dat de praemisse onjuist is, dat de inheemsche bevolking - en hiermede moge ik in dit verband de Creolen bedoelen, waarop ook de schrijver schijnt te duiden (pag. 482/83) - niet werken wil 
en dat met haar niets te bereiken valt, stem ik den schrijver gaarne toe. Dat bewijst de zware en aan ontberingen rijke arbeid in balata-winning en goudbedrijf, evenals de goede diensten, welke de Creolen als vaklieden o.a. in de Bauxite-industrie praesteeren. Doch de afkeer van den Surinamer-Creool in het algemeen van geregelden, nietavontuurlijken arbeid is van te algemeene bekendheid en bovendien ook te goed verklaarbaar, dan dat op deze stelling een theorie in de richting, als waarin de schrijver terecht wil, n.l. de opheffing van Suriname, kan worden opgebouwd. Naast liefde en achting voor zijn landgenooten behoort men bij de behandeling van een zoo belangrijke quaestie als deze ook een open oog te hebben voor de werkelijkheid en die is toch wel deze, dat de groote landbouw als verreweg de voornaamste factor voor het herstel moet worden beschouwd en dat voor dien landbouw alleen oosterlingen - en dan nog wel in hoofdzaak Javanen - als de beste arbeidskrachten moeten worden aangemerkt. Hiermede wil ik natuurlijk allerminst beweren, dat er bij dit verheffingsproces voor den Creool geen plaats zou zijn. Dat is — zooals gezegd — op Moengo en elders reeds gebleken, maar een fout is het, de oplossing der moeilijkheden te baseeren op den bloei van den kleinen landbouw en de geschiktheid van den Creool daarvoor.

In de eerste plaats toch zal het kleinbedrijf in den landbouw voorloopig en vermoedelijk steeds beschouwd moeten worden als een complement op het groot bedrijf, in welks toenemenden bloei dat kleinbedrijf zal deelen en waarvoor het inderdaad van zijn kant van zeer veel belang kan zijn (o.a. als reserve voor arbeidskrachten en leverancier van dagelijksche levensbehoeften).

In de tweede plaats is tot nu toe allerminst bewezen, dat de Creool voor dat klein bedrijf zoo zeer geschikt is. Juist het voorbeeld van den Saramaccapolder, dat de schrijver op pag. $485 / 88$ anhaalt, is geen gelukkige illustratie van zijn bewering.

Ook wil mij de meening, dat van Suriname geen arbeidskolonie te maken is, eenigszins voorbarig voorko- 
men. Ongetwijfeld juist is, dat, indien een speciaal product als b.v. de Delitabak in Suriname kon worden geteeld, de opbloei der kolonie (en dan in een zeer snel tempo vermoedelijk!) te bereiken zou zijn. Doch waarom zouden koffie, suiker en vooral katoen niet hetzelfde - zij het dan ook in gestadiger tempo - kunnen bewerkstelligen? Een bevestigend antwoord hierop mag op grond der geschiedenis zeker worden gegeven en te gereeder, nu de mogelijkheid geopend is, de concurrentievoorwaarden met andere, gelijke producten leverende streken te verbeteren.

Op pag. 493 geeft de schrijver een inderdaad origineel beeld als aanduiding van zijn wenschen. Hij vergelijkt den huidigen toestand met een ,topzwaar ondoordacht geconstrueerd gebouw" en geeft dan aan, hoe de nieuwe constructie zal moeten worden ontworpen en uitgevoerd. Hierbij houdt hij nu echter te veel vast aan zijn voorstelling van het verbeteren van een verzakt gebouw en komt daardoor tot niet steeds juiste conclusies; waarom kan b.v. immigratie van Javanen niet als opnieuw opbouwen worden beschouwd? De gedachte van zooveel mogelijk zelf te doen, is zeker sympathiek, maar practisch niet uitvoerbaar. Zeer juist is de raad, de staatsinmenging zoo gering mogelijk te laten zijn en aan handel en nijverheid goede gelegenheid te bieden voor hun ontwikkeling.

Het is uiteraard niet doenlijk, bij alle détailpunten van het program van den Heer Brandon stil te staan. Daarom moge worden volstaan, met hier en daar enkele grepen te doen en aldus de belangrijkste punten naar voren te brengen.

Zoo is er dan in de eerste plaats het voorstel tot herziening der Surinaamsche staathuishouding, beschouwd aan de hand van de Surinaamsche begrooting voor 1923. Zeer terecht laakt de schrijver het verleenen van subsidie en het voortdurend voorkomen van tekorten op de begrooting en bepleit hij een zoodanige scheiding in die begrooting, dat ,,de Surinaamsche gemeenschap haar huis„,houden voert op eigen kosten en met eigen middelen den 
„grondslag kan leggen van hare welvaart”. Wel zal dan volgens hem de rentebetaling en aflossing der uitstaande leeningen voor rekening van het moederland moeten komen, doch zal verder aan Suriname niet meer mogen worden geleend. Of aldus het subsidie van $f$ 4.000.000.- zou dalen tot een bedrag van $f$ 1.000.000. - kan ik nietnagaan al lijkt mij dit wel iets te gunstig voorgesteld en al komt mij de vraag gewettigd voor, of na overneming dezer lasten het moederland Suriname geheel zal kunnen loslaten. $\mathrm{Na}$ alle jaren van misère schijnt deze overgang wat al te kras en komt het mij verstandiger voor, dezen geleidelijker te doen plaats vinden, zooals ook in de nota van den Ondernemersraad is uiteengezet. Ook wil het mij beter toeschijnen, de verkeersmiddelen voorloopig in handen te laten van het Gouvernement, ook al zullen daardoor de lasten van de koloniale huishouding niet direct worden verminderd, omdat ook al weder in den overgangstijd dergelijke proefnemingen gevaarlijk zijn, terwijl het hoogst twijfelachtig is, of voor den spoorweg althans op het oogenblik een gegadigde voor de exploitatie te vinden zou zijn. Wel verre van een voorstander van overheidsbedrijven à outrance te zijn, meen ik toch, dat zoolang geen gezond economisch herstel is ingetreden, de kans groot is; dat een eventueele particuliere exploitant der verkeersmiddelen - aangenomen, dat hij zou opdagen! - spoedig de onderneming zou moeten liquideeren met het gevolg, dat dan de met zooveel kosten en moeiten verkregen verbindingen teloor zouden gaan of toch weder door het Gouvernement zouden moeten worden overgenomen.

Op het gebied der belastingwetgeving geeft de Heer Brandon weder van groote originaliteit in denkbeelden blijk. Daar alle belasting in laatste instantie volgens hem moet voortkomen uit inkomen of verdienste en het inkomen wordt besteed, om goederen te koopen, wordt „practisch het totale inkomen van de gemeenschapsleden „naar den handelaar - in den ruimsten zin op te vatten "- gebracht." Daarom wil hij die handelaren laten optreden als de belastinginners der gemeenschap, waarbij 
dan aan een systeem van indirecte belastingen en in zonderheid aan een verteringsbelasting wordt gedacht. Deze gedachte wordt verder practisch uitgewerkt en hare voorgeelen worden opgesomd, terwijl ook de nadeelen niet worden vergeten, waaronder vooral voor iemand, die blijkens deze zijn studie veel voor den klein-ondernemer gevoelt, op den voorgrond moest treden, dat aldus de groote gezinnen zwaarder worden getroffen dan de kleine en dan alleenstaande personen. Om dit te verhinderen, wil hij deze categorieën bij wijze van compensatie tegemoet komen met schoolgeld, medicijnen en geneeskundige behandeling. Hieruit volgt reeds, dat wij ons hier op een verkeerden weg zouden begeven. Het belastingstelsel zal ongetwijfeld grondig moeten worden herzien en in deze richting doet meergenoemde nota van den Ondernemersraad dan ook concrete voorstellen, waarop thans niet nader kan worden ingegaan, doch een grondbeginsel zal moeten zijn, dat ieder naar zijn vermogen in de staathuishouding bijdraagt en dat noch de handel onnoodig wordt belast noch ook de levensbehoeften onnoodig duurder worden gemaakt.

Tenslotte wijdt de schrijver in dit verband eenige beschouwingen aan een herziening van de inrichting van het bestuursapparaat. Dit is al herhaaldelijk een mikpunt voor aanvallen van verschillende zijden geweest en al moge worden toegegeven, dat het voor de thans te verrichten taak te groot is, dit neemt niet weg, dat de opzet zeer geschikt is voor een zich gestadig uitbreidende gemeenschap en het derhalve zeer ongewenscht zoude zijn, daarin op dit oogenblik ingrijpende veranderingen aan te brengen. Tegen de voorstellen van den Heer Brandon vooral waar zij beoogen, de positie van den Gouverneur te wijzigen, moet in verband met het groote belang van het handhaven der Rijksgedachte ernstig bezwaar worden gemaakt. Wel zegt de schrijver op pag. 513, dat de Gouverneur de representant van het Opperbestuir moet worden (is hij dat dan thans niet?!), maar even verder schrijft hij, dat het eigenlijke Koloniaal Bestuur moet worden gevormd door den Raad van Suriname of Raadpensionaris, 
een nieuwe titularis dus en de Koloniale Staten, die tezamen het uitvoerend gezag uitmaken, terwijl het wetgevend gezag dan zou berusten bij den Gouverneur, Raad van Suriname en Koloniale Staten tezamen. Over dien Raadspensionaris zegt de Heer Brandon op pag. 519, dat hij zich dien denkt ,,als een zeer belangrijke functionaris „met een geheel eigen zelfstandige positie naast den Gou„verneur staande en evenals deze door de Koningin te be„noemen. Hij is het feitelijke Hoofd van de Koloniale Ge„meenschap, de eerste burger van Suriname. Hij vormt „de permanente schakel tusschen den Gouverneur als „zaakgelastigde van den Minister van Koloniën en de Ko„loniale Staten als gezagscollege van de Koloniale Ge"meenschap. Tevens is hij de regelaar van de goede sa„menwerking tusschen de beide onderdeelen van het „hoofdbestuursmechanisme Koloniale Staten en Alge"meen Landskantoor".

Hierbij wordt den Koloniale Staten de taak toegedacht van het maken van ,de verschillende wetsregelingen van „algemeenen aard (verordeningen)" en het vaststellen van het "program van overheidswerkzaamheden", terwijl het Algemeen Landskantoor de verordeningsontwerpen technisch „,resumeert”, de uitvoeringsregelingen opstelt, de plannen opmaakt voor de uit te voeren werken en de financieele gevolgen berekent.

Nog afgezien daarvan, dat de voorgestelde wijzigingen allerminst belangrijke bezuinigingen zullen tengevolge hebben, is het niet duidelijk, waarom zij van staatsrechtelijk standpunt bezien noodzakelijk zijn. Met name is de functie van den Raadpensionaris in een stelsel, dat de juiste verhouding tusschen moederland en Suriname weergeeft en tevens een behoorlijke verdeeling van verantwoordelijkheid der koloniale organen beoogt, niet te verdedigen. Is het al niet duidelijk, welk voordeel deze verandering volgens het systeem van den Heer Brandon zou doen ontstaan, met de Rijksgedachte is dit nieuwe instituut ten eenen male in flagranten strijd. Hier wordt naast den Gouverneur, de belichaming dier gedachte, een ambtenaar geplaatst, wel eveneens door de Kroon benoemd, 
maar overigens geheel zelfstandig. Uit niets blijkt, aan wien hij verantwoording schuldig is en tot wien hij in hierarchische verhouding staat. Dat hij voorzitter is van de beide naast elkander op eigenaardige wijze aan wetgeving en uitvoering medewerkende colleges, de Koloniale Staten en het Algemeen Landskantoor, lost deze vraag natuurlijk niet op. De huidige staatsinrichting is voldoende berekend op een eventueele toepassing der koloniale autonomie en zal dit na de herziening van het thans geldende Regeeringsreglement nog beter zijn, mits in het voorstel van wet, dat daarop betrekking heeft en toch nog wel eens in behandeling zal komen, niet ter elfder ure wijzigingen in den geest van de voorstellen van den Heer Brandon worden aangebracht.

In het tweede gedeelte van zijn bijdrage geeft de schrijver onder IV (pag. 528/559) een „Schetsontwerp”, volgens hetwelk naar zijn meening aan de ontwikkeling van Suriname moet worden gewerkt. Hierin komen zeer juiste opmerkingen voor over onderwijs, propaganda voor den ladbouw, lichamelijke ontwikkeling en hygiënische opvoeding, goedkoope arbeidsmarkt en goedkoopen grond. $\mathrm{Na}$ deze algemeene en belangrijke beschouwingen komt hij dan tot de verdere uitwerking, welke over vijf punten wordt verdeeld. In de eerste plaats wordt jaarlijksche immigratie van 1200 à 1600 volwassen contractanten uit Oost-Indië onder poenale sanctie aanbevolen. Een fout hierbij is m.i. echter, dat de Heer Brandon voor de kosten dezer immigratie van de werkgevers een retributie wil vorderen. Herhaaldelijk is reeds betoogd, dat, aangezien bevolkingsaanvoer een eerste vereischte is voor een volledig economisch herstel, de kosten van dezen aanvoer op de gemeenschap moeten drukken en niet op de werkgevers. Met deze zienswijze hebben zich dan ook onlangs zoowel de Minister als de Tweede Kamer vereenigd.

Dan wordt gepleit voor een hoofdweg in Oost-Westelijke strekking van Albina over Paramaribo en Coronie naar Nickerie en ontbossching langs dien weg ten behoeve van polders. Dit is inderdaad een voortreffelijk plan, 
daar het werk verschaft, waarvoor de Creolen geschikt geacht moeten worden en tevens dient tot "opening" van een zeer vruchtbare streek. Hier zouden de belangen van groot- en kleinbedrijf in den landbouw zeer wel samen kunnen gaan. Zooals bekend is, is een begin van dezen weg reeds in aanleg, zij het dan ook op andere wijze dan door den Heer Brandon en mij gedacht. Zeer te loven is het in ieder geval, dat met dezen noodzakelijken maatregel eindelijk een aanvang is gemaakt.

In de vierde plaats stelt de schrijver voor, de ontwerping en toepassing van een soort ,cultuurstelsel”, teneinde aldus de productie voor den kleinen landbouwer loonend en aantrekkelijk te maken. Hij wil het stelsel-van den Bosch niet klakkeloos overgenomenzien, maarwenscht het goede uit de grondgedachte in practijk te brengen. Zooals boven reeds is gezegd, komen deze en dergelijke maatregelen eerst aan de orde, wanneer een aanmerkelijk grootbedrijf in den landbouw is gevestigd, al was het reeds daarom, omdat de kleine landbouwer anders geen behoorlijk afzetgebied voor zijn producten zal vinden, maar dan verdient het denkbeeld ten zeerste ernstige overweging en dan zal het van belang blijken, dat hier door den Heer Brandon een zeer uitvoerig uitgewerkt systeem is ontworpen.

Tenslotte komt de schrijver op voor de organisatie van een Gouvernements opkoop- en exportdienst met het doel, ,den afzet van de gewonnen producten naar het bui„tenland te verzekeren en gaandeweg zoo voordeelig mo"gelijk te doen geschieden". Deze dienst wordt uitsluitend als controleorgaan gedacht en mag niet zelfstandig uitvoeren. Deze maatregel kan m.i. van belang zijn, om een markt voor een bepaald product of bepaalde producten te helpen veroveren, door aldus een garantie van qualiteit te geven (men denke aan vruchten en rijst), doch daarna trede zij terug als zijnde in strijd met de beginselen van vrijhandel, waaraan helaas in den laatsten tijd, zij het vaak onder den drang van moeilijke omstandigheden, herhaaldelijk hier en elders geweld wordt aangedaan.

In zijn „Slotoverdenking” komt de Heer Brandon dan 
tot de conclusie, dat Suriname slechts op twee manieren „tot een bevredigenden staat van economische ontwikke"ling en maatschappelijke welvaart" kan worden gebracht en wel òf op de manier van het Suriname-StudieSyndicaat door „verbouwing en uitbouwing van de be„staande economische structuur volgens de principes van „het arbeidskolonieplan” ò op de door den schrijver voor„gestane wijze volgens de beginselen van een ,tropen-ves„tigingskolonie, gebouwd op de bestaande personeele en „materieele krachten en middelen in het land zelf aan„wezig".

Uit het voorafgaande is reeds gebleken, dat naar mijn meening een algeheel herstel alleen langs den weg, door den Heer Brandon aangewezen, niet zal kunnen worden bereikt, doch bij de uitwerking van een plan, zooals thans in de begrooting voor 1927 in groote lijnen is aangegeven, zal met verschillende opmerkingen van den schrijver met vrucht rekening kunnen worden gehouden, terwijl, is eenmaal een bloeiend grootbedrijf in den landbouw gevestigd, meer dan een van zijn voorstellen voor de ontwikkeling van een gezond klein-landbouwbedrijf van veel belang kunnen zijn.

Bloemendaal, 7 April 1927. 